\title{
Vibration and Stress Response of High-Speed Train Gearboxes under Different Excitations
}

\author{
Wangang $\mathrm{Zhu}{ }^{1,2}$, Wei Sun ${ }^{1}$ and Hao $\mathrm{Wu}^{3, *}$ \\ 1 School of Mechanical Engineering, Dalian University of Technology, Dalian 610023, China; \\ 13753157458@163.com (W.Z.); sunwei@dlut.edu.cn (W.S.) \\ 2 Taiyuan Heavy Industry Rail Transit Equipment Co., Ltd., Taiyuan 300082, China \\ 3 College of Mechanical and Vehicle Engineering, Chongqing University, Chongqing 400044, China \\ * Correspondence: haowu@cqu.edu.cn
}

check for updates

Citation: Zhu, W.; Sun, W.; Wu, H. Vibration and Stress Response of High-Speed Train Gearboxes under Different Excitations. Appl. Sci. 2022, 12, 712. https://doi.org/10.3390/ app12020712

Academic Editor: Hong-Zhong Huang

Received: 14 November 2021

Accepted: 7 January 2022

Published: 12 January 2022

Publisher's Note: MDPI stays neutral with regard to jurisdictional claims in published maps and institutional affiliations.

Copyright: (c) 2022 by the authors. Licensee MDPI, Basel, Switzerland. This article is an open access article distributed under the terms and conditions of the Creative Commons Attribution (CC BY) license (https:// creativecommons.org/licenses/by/ $4.0 /)$.

\begin{abstract}
The vibration data of the gearbox on a high-speed train was measured, and the vibration characteristics were analyzed in this paper. The dynamic stress of the gearbox under the internal and external excitation was examined by a railway vehicle dynamic model with a flexible gearbox and a flexible wheelset. The ideal 20th polygonal wear was considered, and dynamic stresses of the gearbox under different polygonal wear amplitudes were calculated. The gear transmission model was established to study the dynamic stress of the gearbox under the influence of the timevarying stiffness of the gear meshing. Based on the rigid-flexible coupling model, and considering the influence of wheel polygonization, gear meshing time-varying stiffness, and wheelset elastic deformation, the dynamic stress of the gearbox was investigated with consideration of the measured polygonal wear and measured rail excitation. The results show that the dynamic stress of the gearbox is dominated by the wheel polygonization. Moreover, not only the wheel polygonization excites the resonance of the gearbox, but also the flexible deformation of the wheelset leads to the deformation of the gearbox, which also increases the dynamic stress of the gearbox. Within the resonant bandwidth of the frequency, the amplitude of the dynamic stresses in the gearbox will increase considerably compared with the normal case.
\end{abstract}

Keywords: railway vehicle; rigid-flexible coupling; wheel polygonization; dynamic stress of gearbox; vibration analysis

\section{Introduction}

As a critical component of a high-speed train mechanical traction drive system, the primary function of the gearbox is to transmit the power of the motor to the wheelset. With the increase in train operating speed, the mechanical performance of the train at high speed is affected by various sources of excitation, such as the frequency range of vibration, which is significantly higher than that of conventional trains. These sources of excitation were not evident in low-speed trains in the past. Gearboxes of high-speed trains have been working in very harsh conditions for a long time. The manufacturing of machinery and equipment is more focused on high reliability and long service life [1-4]. Hence, it is of great engineering significance to study the dynamic response of the gearbox under the complicated internal and external excitation.

The high-speed train gearbox has special working environment in comparison with gear transmission systems in machine tools, aviation, wind turbines, etc. [5-8]. The gear wheel is fixed on the wheelset axle directly through interference fit, and the gearbox housing is hinged with the wheelset axle through bearing; due to this installation method, the vibration of the wheelset will be transferred to the gearbox directly. The wheelsets and tracks of trains are made of steel. Due to manufacturing errors, installation errors, and wear and tear, rigid shocks are generated between the wheels and tracks when the vehicle is running, which is the main source of excitation for high-speed train gearboxes. As the 
mileage of high-speed trains increases, the uneven wear of the wheels in the circumferential direction makes the wheel-rail impact more and more serious, which leads to a sharp increase in the amplitude of the vibration of the gearbox. Figure 1 is a photograph of the uneven wear that occurs in the wheels of high-speed trains, a phenomenon known as wheel polygonal wear. Figure 2 shows the evolution trend of vibration acceleration of high-speed train gearboxes with operating mileage obtained from long-term tracking tests.

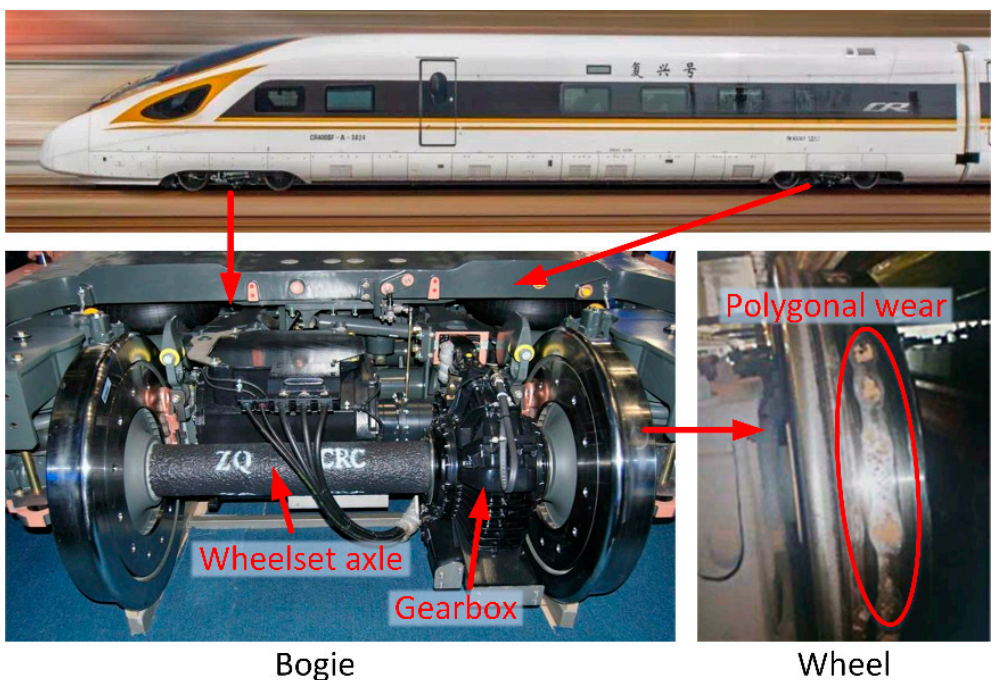

Figure 1. Wheel polygonal wear.

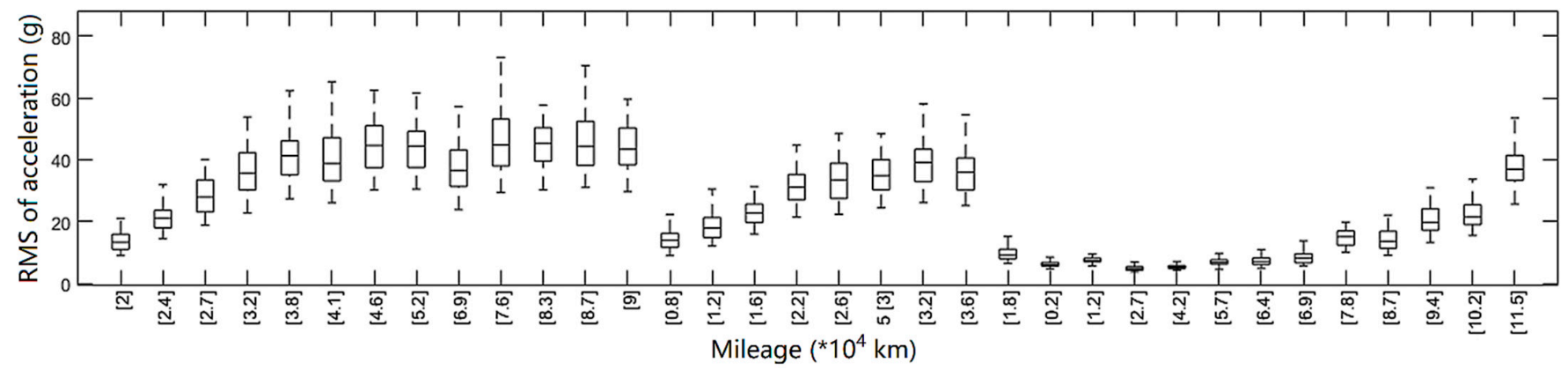

Figure 2. The evolution trend of vibration acceleration of high-speed train gearboxes with operating mileage.

Vibration fatigue and reliability problems of mechanical systems have received a great deal of attention from researchers [9-12]. A great deal of work has been done in the field of railroad vehicles, which focuses on the effect of internal excitation sources on gearboxes [13-16]. Previous studies [17-19] have shown that the wheel polygonization will lead to a surge in vibration response of various components of the vehicle. Wu et al. [20,21] used an intelligent algorithm to improve the accuracy of the gearbox model and studied the influence of harmonic traction torque on the vibration and stress of the gearbox. Huang et al. [22] established a dynamic model of a high-speed train and a finite element model of the gearbox housing and analyzed the influence of internal excitation (the periodic variation of meshing stiffness) and external excitation (rail excitation, harmonic traction torque). Wang et al. [23] established a multi-body dynamic model of a high-speed train with flexible gearbox housing to investigate the influence of the wheel polygonization on the dynamic response of the gearbox housing.

Gearbox excitation sources in high-speed trains can be divided into external sources and internal sources. There are three external excitation sources according to the connection between the other components and the gearbox, which are the wheelset, the motor, and 
the bogie frame [24,25]. It should be mentioned that the excitation from the bogie frame is generated by another two excitation sources coupling. The internal excitation is caused by the time-varying stiffness of the gear meshing [13]. It can be seen from the above analysis that the gearbox on the railway vehicle is in a nonlinear system with multi-input and high-frequency coupling.

In this paper, the finite element model of the gearbox was established to analyze eigenmodes, and the multi-body dynamics model of the high-speed train was established to calculate the dynamic response of the gearbox. The gearbox and the wheelset were considered as flexible bodies, a rigid-flexible coupling model was established. Based on this model, the excitation sources inside and outside the gearboxes were analyzed, respectively, and the influence of each excitation source on the dynamic stress of the gearbox housing was studied.

\section{Modeling of High-Speed Train with Gear Transmission}

\subsection{Multibody System Dynamics Model}

The typical high-speed train model of China was established in this study, as shown in Figure 3, which is composed of a car body, two bogies, and four wheelsets. Each wheelset is mounted with a traction motor and a gear transmission system. The detailed model has been illustrated in Reference [20], and the total degrees of freedom of the train model are listed in Table 1. The primary suspension parameters of the train are given in the literature [17]. The dynamic model of the gear transmission system has been illustrated in Reference [26]. The main design parameters of the gear transmission are listed in Table 2. The multi-body dynamic model is established by Simpack. The formula of motion of the multi-body dynamic model is as follows:

$$
M \ddot{x}+C \dot{x}+K x=F
$$

where $M, C, K$ are the mass matrix, the damping matrix, and the stiffness matrix, respectively. $X$ is the displacement vector and $F$ is the vector of loads.

Table 1. Degrees of freedom for the railway vehicle.

\begin{tabular}{|c|c|c|c|c|c|c|c|}
\hline \multirow{2}{*}{ Vehicle Model } & \multicolumn{6}{|c|}{ Type of Motion } & \\
\hline & Longitudinal & Horizontal & Vertical & Roll & Yaw & Pitch & \\
\hline Carbody & $X_{c}$ & $Y_{c}$ & $Z_{c}$ & $\phi_{c}$ & $\psi_{c}$ & $\beta_{c}$ & \\
\hline Bogie frame & $X_{b i}$ & $Y_{b i}$ & $Z_{b i}$ & $\phi_{b i}$ & $\psi_{b i}$ & $\beta_{b i}$ & $i=1 \sim 2$ \\
\hline Wheelset & $X_{w i}$ & $Y_{w i}$ & $Z_{w i}$ & $\phi_{w i}$ & $\psi_{w i}$ & $\beta_{w i}$ & $i=1 \sim 4$ \\
\hline Stator & $X_{m i}$ & $Y_{m i}$ & $Z_{m i}$ & $\phi_{m i}$ & $\psi_{m i}$ & $\beta_{m i}$ & $i=1 \sim 4$ \\
\hline Rotor & & & & & & $\beta_{r i}$ & $i=1 \sim 4$ \\
\hline Gear wheel & & & & & & $\beta_{p i}$ & $i=1 \sim 4$ \\
\hline Pinion wheel & & & & & & $\beta_{g i}$ & $i=1 \sim 4$ \\
\hline Gearbox housing & & & & & & $\beta_{g b i}$ & $i=1 \sim 4$ \\
\hline
\end{tabular}

Table 2. Main design parameters of the gear transmissions.

\begin{tabular}{ccc}
\hline \multirow{2}{*}{ Specification } & \multicolumn{2}{c}{ Value } \\
\cline { 2 - 3 } & Pinion & Gear \\
\hline Tooth shape & Involute & Involute \\
Material & Steel & Steel \\
Normal module & $6 \mathrm{~mm}$ & $6 \mathrm{~mm}$ \\
Normal pressure angle & $20^{\circ}$ & $20^{\circ}$ \\
Dedendum diameter & $222 \mathrm{~mm}$ & $522 \mathrm{~mm}$ \\
Addendum diameter & $195 \mathrm{~mm}$ & $495 \mathrm{~mm}$ \\
Flank width & $65 \mathrm{~mm}$ & $65 \mathrm{~mm}$ \\
Number of teeth & 35 & 85 \\
\hline
\end{tabular}


The wheel-rail contact force is evaluated by the Hertzian nonlinear contact theory, which can be expressed as follows:

$$
f_{i}(t)=\left\{\begin{array}{cl}
\left(\frac{1}{G} \delta Z_{i}(t)\right)^{\frac{3}{2}} & \text { if } \delta Z_{i}(t)>0 \\
0 & \text { if } \delta Z_{i}(t) \leq 0
\end{array}\right.
$$

where $G$ is the wheel-rail contact constant and $\delta Z_{i}(t)$ is the elastic compression deformation of the $i$ th wheelset and rail at the contact point in the normal direction, as follows [17]:

$$
\delta Z_{i}(t)=Z_{\omega i}(t)-Z_{r}\left(x_{i}, t\right)-Z_{0 i}(t)(i=1 \sim 4)
$$

where $Z_{\omega i}(t)$ is the displacement of the $i$ th wheelset, $Z_{r}\left(x_{i}, t\right)$ is the rail displacement under the $i$ th wheelset, and $Z_{0 i}(t)$ is the track irregularity under the $i$ th wheelset.

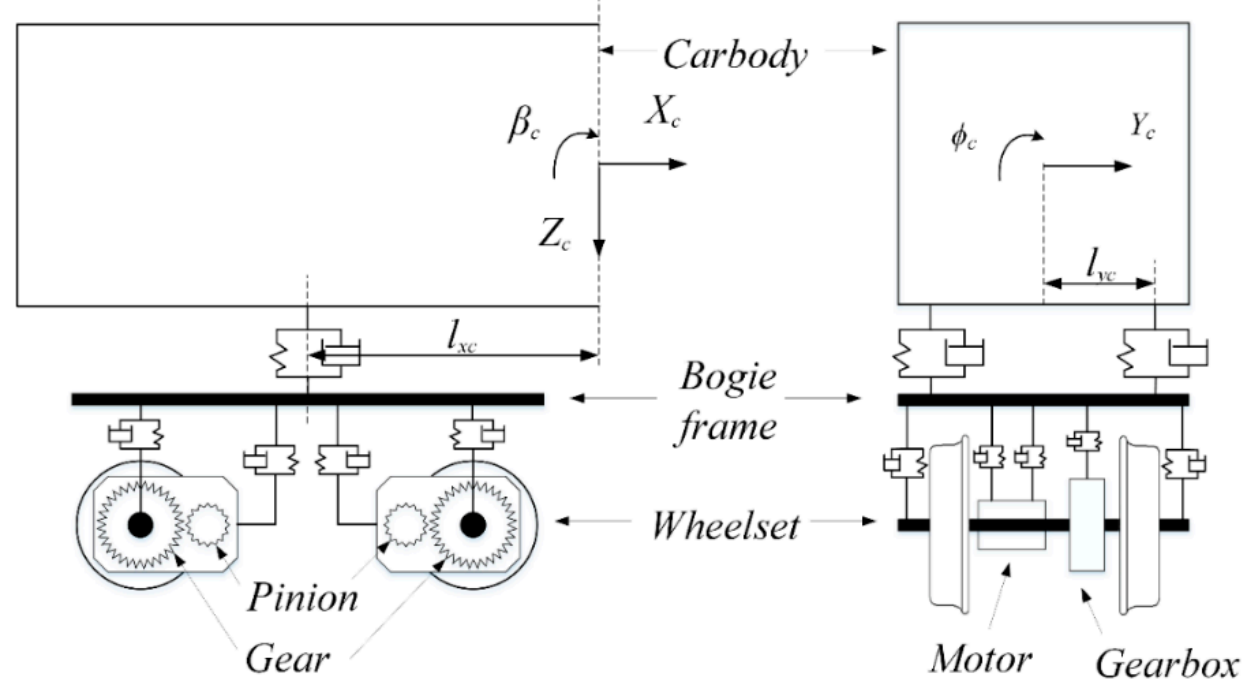

Figure 3. Vehicle system dynamics model.

\subsection{Finite Element Model}

The gearbox finite element model was established to carry on the modal analysis, as shown in Figure 4. Due to the complex structure of the gearbox, Abaqus was used to build the finite element model of the gearbox. To accurately simulate the actual working environment of the gearbox, the boundary conditions of the model were set as follows: the gear and pinion wheel bearing bores of the gearbox are coupled to their respective center points and constrained the translation in $X, Y, Z$-axis and the rotation in $X, Z$-axis around the center of the gear bearing bore. The upper and lower planes of the bracket are coupled to the same suspension point and connected with the mass of the bogie frame by a spring. The mass of the bogie frame is connected with the foundation by a spring. The stiffness of each spring is set in accordance with the actual stiffness of the connecting parts of the gearbox. The wheelset does not have any degree of freedom constraints, so the free modality of the wheelset is calculated directly.

The results of mode shapes and modal frequencies are shown in Figures 4 and 5. It can be seen that there are two modal frequencies of the wheelset, which are $338 \mathrm{~Hz}$ and $381 \mathrm{~Hz}$ in the frequency band of $300 \sim 400 \mathrm{~Hz}$; the gearbox housing has a $405 \mathrm{~Hz}$ mode in the frequency band of $400 \sim 500 \mathrm{~Hz}$; in the frequency band of $500 \sim 600 \mathrm{~Hz}$, there is a $578 \mathrm{~Hz}$ mode of the gearbox housing as well as a $591 \mathrm{~Hz}$ mode of the wheelset; the gearbox housing has a $927 \mathrm{~Hz}$ mode near to the frequency of $900 \mathrm{~Hz}$. 


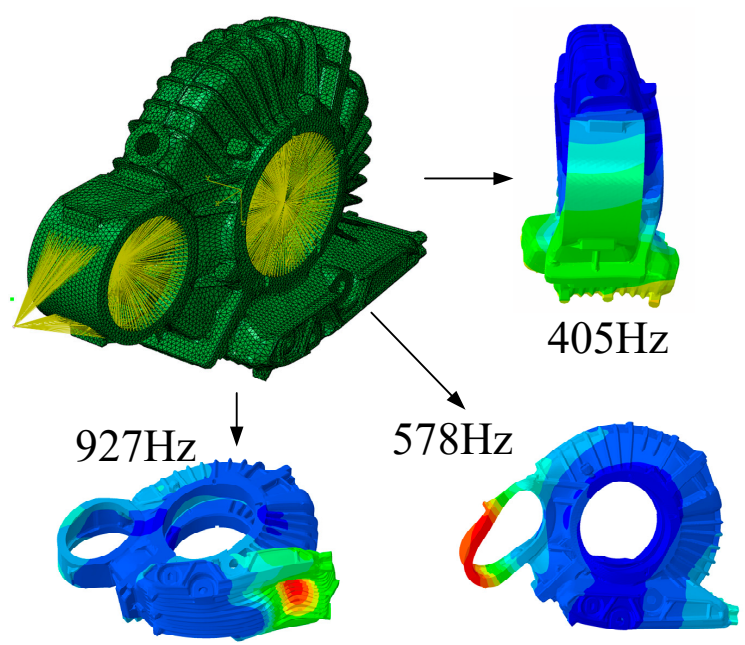

Figure 4. Gearbox modality.

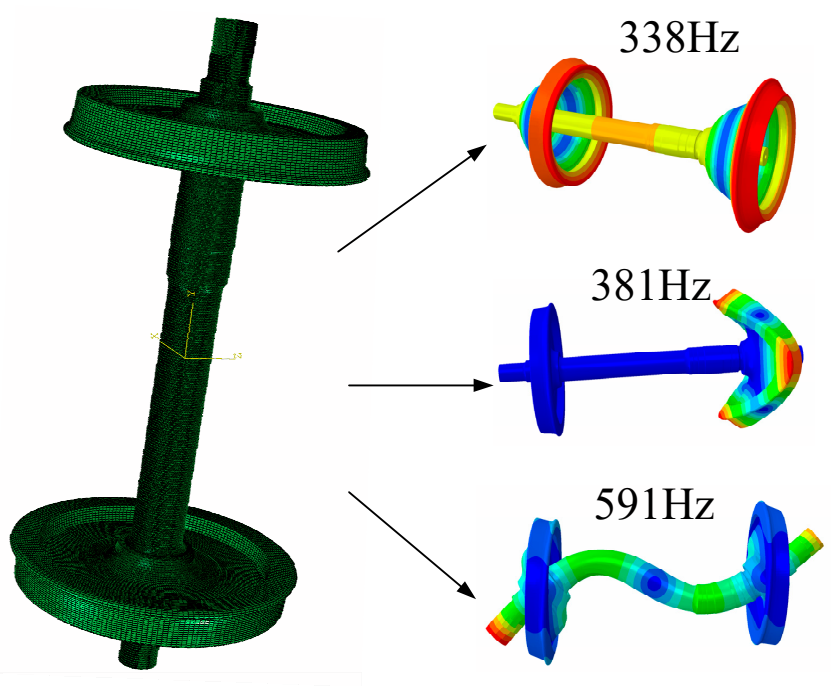

Figure 5. Wheel set modality.

The flexible models of the gearbox housing and the wheelset were established by the finite element method to evaluate the high-frequency response of the gearbox housing induced by the wheel polygonization. The detailed method used to describe the flexible body in the multi-body dynamic model refers to [27-29]. The stress of gearbox housing can be calculated by the modal stress recovery method [30-32].

\subsection{Model Verification with Measured Data}

A line test was conducted on a high-speed train gearbox in China to study the vibration characteristics of the gearbox of the high-speed train. The B\&K vibration transducers were used to measure the vibration acceleration of the gearbox and the axle box on the wheelset. The signals of each measurement point were continuously collected by the eDAQ data recording system as shown in Figure 6, which can ensure the authenticity of the sampled data; the test system has high accuracy, fast dynamic response, and can achieve continuous sampling throughout the test, thus ensuring the completeness of the test data. The data sampling frequency in the test is $10 \mathrm{kHz}$. Points 1 and 2, respectively, measured the vertical and the lateral vibration acceleration of the gearbox. Point 3 measured the vertical vibration acceleration of the axle box on the wheelset. 


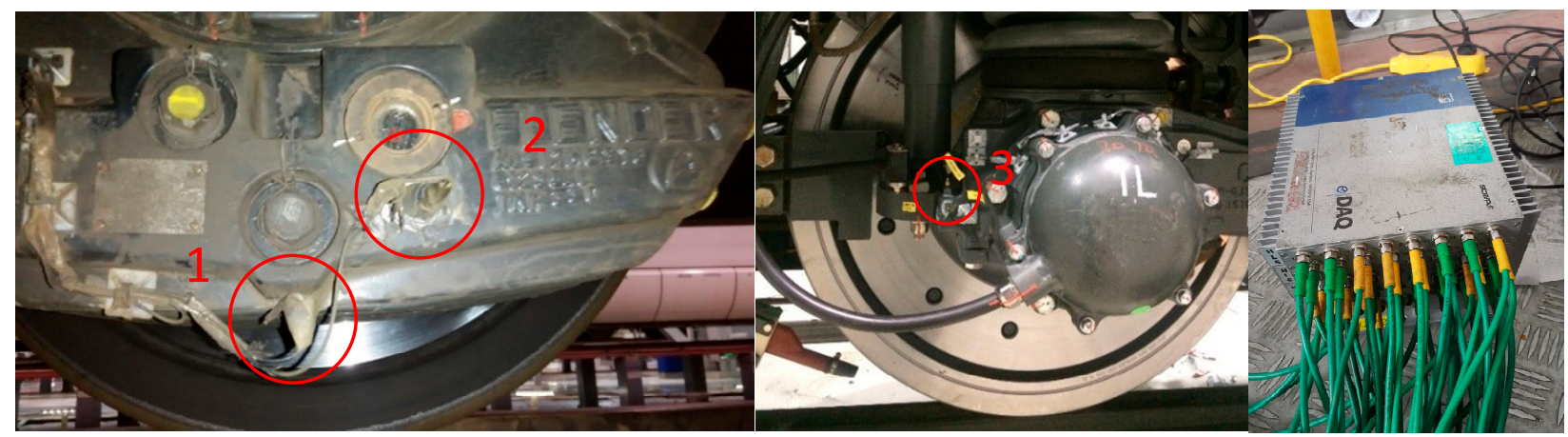

Figure 6. Measuring points of gearbox and axle box.

The above system was used to measure the vibration acceleration in both directions of the gearbox and the axle box on the wheelset during the whole operation of the tractionuniform-braking of the high-speed train. The vertical vibration acceleration of the axle box and gearbox at the speed of $300 \mathrm{~km} / \mathrm{h}$ is as shown in Figure 7 . The vibration acceleration amplitude reaches a maximum of $600 \mathrm{~m} / \mathrm{s}^{2}$, and the RMS value is $63.6 \mathrm{~m} / \mathrm{s}^{2}$. We performed a fast Fourier transformation (FFT) on the vibration acceleration signal to obtain the frequency spectrum characteristics of the vibration acceleration of gearbox and axle box, as shown in Figure 8. It can be seen from the spectrum diagram that there are multiple main frequency vibrations in the axle box and gearbox. Since the wheel radius is $0.434 \mathrm{~m}$, it is calculated that $30.6 \mathrm{~Hz}$ is the wheelset rotation frequency when the train is running at the speed of $300 \mathrm{~km} / \mathrm{h}$; this was to more intuitively express the main frequency of the vibration in the frequency spectrum chart, so that the frequency of the wheelset is presented as $\mathrm{f}$, so another main frequency can be expressed as multiples of $\mathrm{f}$. According to the spectrum diagram, it can be analyzed that there are obvious 1st order polygonal wear and 17th-19th order polygonal wears of the wheelset.

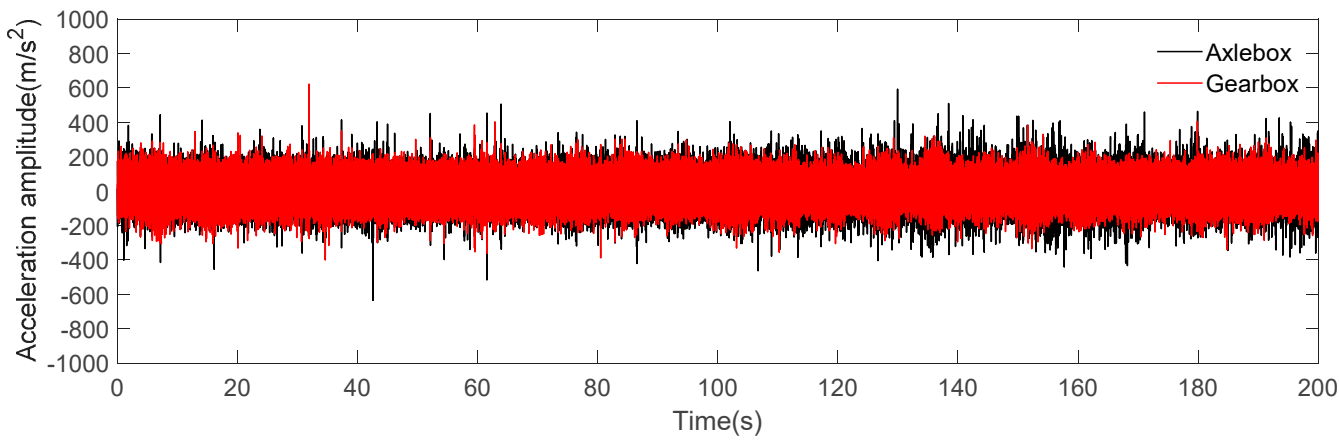

Figure 7. Vibration of gearbox and axle box.

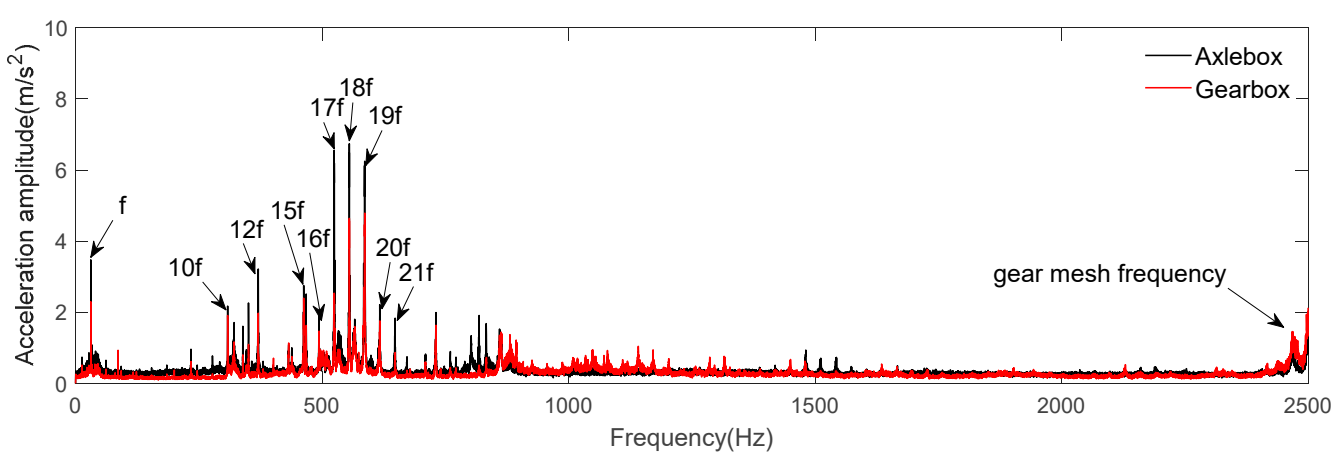

Figure 8. Spectrum of gearbox and axle box. 
Comparing the vibration components of the axle box and gearbox at each main frequency in the frequency domain, it can be seen that the vibration of the axle box is greater than that of the gearbox at $\mathrm{f}$ and $17 \sim 19 \mathrm{f}$, while the vibration of the gear box is greater than that of the axle box at the gear meshing frequency. This is because the gear mesh is the internal excitation of the gearbox, the vibration energy at this frequency is generated by the gearbox and transferred to the axle box through the wheelset, while the vibration energy at the other vibration main frequencies is generated by the wheel-rail contact and transferred to the gearbox through the wheelset.

The short-time Fourier transform (STFT) was performed on the vertical vibration acceleration of the gearbox to verify the above analysis. It can be seen from Figure 9 that during the traction condition of the train, the main vibration frequency of the gearbox increases with the increase in speed. At the constant speed of $300 \mathrm{~km} / \mathrm{h}$, the main frequency of the vibration of the gearbox remains unchanged, and then in the braking condition, the main frequency of vibration decreases with speed. At the constant speed of $300 \mathrm{~km} / \mathrm{h}$, the interval between the main frequencies of each vibration is $30.6 \mathrm{~Hz}$, which indicates that these main frequencies are caused by the polygonal wear of wheels.

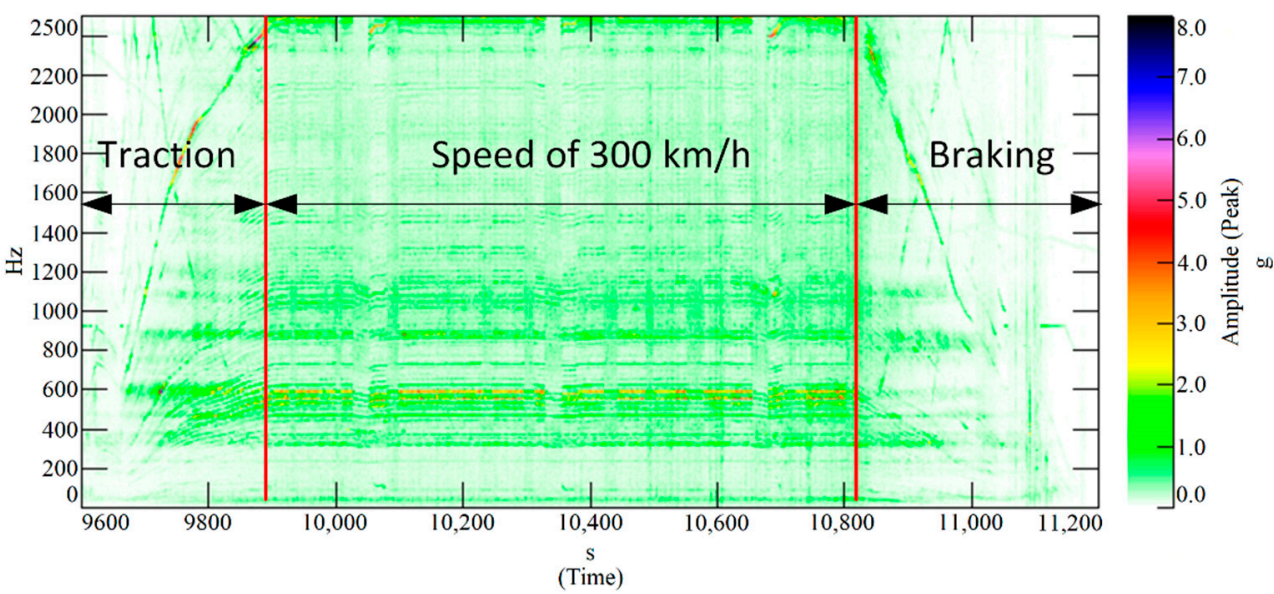

(a)

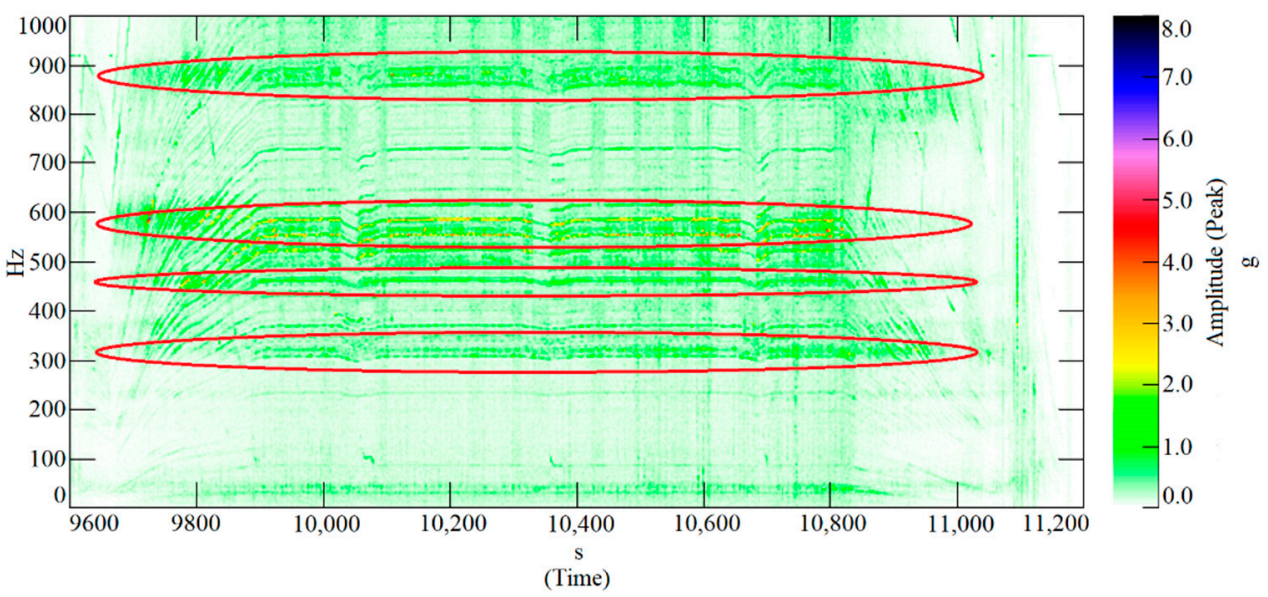

(b)

Figure 9. STFT of the vibration acceleration of gearbox in the frequency range of (a) $0 \sim 2500 \mathrm{~Hz}$ (b) $0 \sim 1000 \mathrm{~Hz}$.

In addition, even if the vehicle operates speed changes, which means the excitation frequency also changes, the amplitudes of the vibration acceleration of the gearbox in the frequency range of $300 \sim 400 \mathrm{~Hz}, 400 \sim 500 \mathrm{~Hz}$, around $600 \mathrm{~Hz}$, and $800 \sim 900 \mathrm{~Hz}$ are still obvious in the whole traction-constant speed-braking operation. The modalities of the 
wheelset or the gearbox in these several frequency ranges are described. The resonance is caused by the superposition of the structural modal frequency and the excitation frequency caused by the polygonal wear of wheels. Due to the limitation of test conditions, the modal test of the gearbox is not performed for the time being.

During traction acceleration, the gearbox has a major vibration frequency that varies with speed, which is caused by gear meshing. The vibration energy concentration near frequencies up to $1800 \mathrm{~Hz}$ and $2400 \mathrm{~Hz}$ indicates that the gearbox shows a resonance phenomenon at this time. However, these two excitation frequencies are only transiently present, and the resonance disappears when the vehicle is running at a constant speed. It is necessary to focus on the fact that the resonance phenomenon at 500 600 Hz (17 19 f) has been existing in the constant speed operation phase, which indicates that the excitation frequency has existed for a long time; moreover, combined with the characteristics of the change of the excitation frequency with speed in the traction and braking phases, it can be identified as the excitation of wheel polygon wear.

Therefore, in the comparison of Figure 9 with Figures 4 and 5, it can be inferred that the vibration in the frequency range of $300 \sim 400 \mathrm{~Hz}$ in Figure 9 is due to the wheel-rail impact excitation causing the wheelset to resonate with the mode of $338 \mathrm{~Hz}$, which results in an increase in the vertical vibration acceleration amplitude of the gearbox. The vibration in other frequency ranges is caused by the gearbox and wheelset coupling together.

\section{Influence of Ideal Excitations on Dynamic Response of Gearbox Housing}

Due to the connection relationship between the gearbox and wheel pair of high-speed trains, the gearbox vibration and wheel pair vibration are coupled with each other. In this section, the vibration and stress response of the gearbox is calculated by using the rigidflexible coupling dynamics model of high-speed trains for three factors: wheel polygon, gearbox traction torque, and wheelset elastic deformation, respectively. The simulation parameters are set as shown in Table 3.

Table 3. Simulation parameters.

\begin{tabular}{ccc}
\hline & Value & Unit \\
\hline Sample frequency & 10,000 & $\mathrm{~Hz}$ \\
Order of the wheel & 20 & \\
polygonization & 0.43 & $\mathrm{~m}$ \\
Wheel rolling circle radius & & \\
\hline
\end{tabular}

\subsection{Effect of Wheel Polygonization}

According to measurement on the wheel polygonization, it can be concluded that the 20th order of the wheel polygonization dominates in most of the wheels of the high-speed train [17]. In order to study the effect of the wheel polygonization on the dynamic stress of the gearbox housing, the ideal 20th order wheel polygonization shown in Figure 10 was considered in the rigid-flexible coupling model of the multi-body system, while the wheel polygons on the left and right sides of the wheelset in the model were considered in the same phase of wear. The amplitudes of both wheels' polygonal wear were $0.01 \mathrm{~mm}$. The wheelset was considered as a rigid body and the traction torque of the gearbox set to $0 \mathrm{Nm}$.

Figure 11 shows the relationship between the wheel-rail contact force and the running speed of the high-speed train. When the velocity is in the range of $100 \sim 360 \mathrm{~km} / \mathrm{h}$, with the increase in speed, the wheel-rail normal force amplitude at the main frequency shows a parabolic trend, reaching the peak value at the $360 \mathrm{~km} / \mathrm{h}$ speed. Nevertheless, when the running speed is higher than $360 \mathrm{~km} / \mathrm{h}$, the amplitude of the main frequency decreases gradually while the speed increases. The reason for this phenomenon is that the wheel-rail system has an eigenmode around $750 \mathrm{~Hz}$, and when the excitation frequency of the wheel polygonization is coupled with the eigenfrequency, the resulting wheel-rail impact energy reaches its peak. 


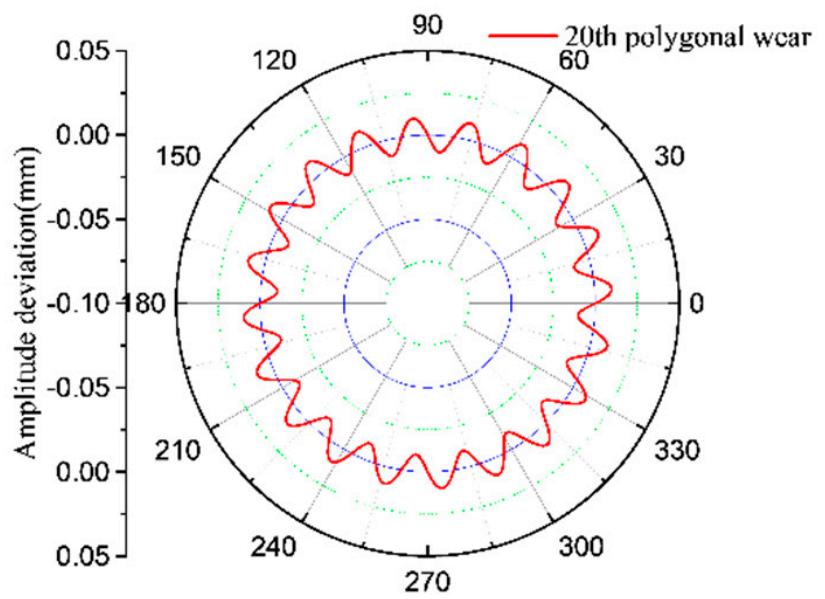

Figure 10. Wheel polygonization used in simulation.

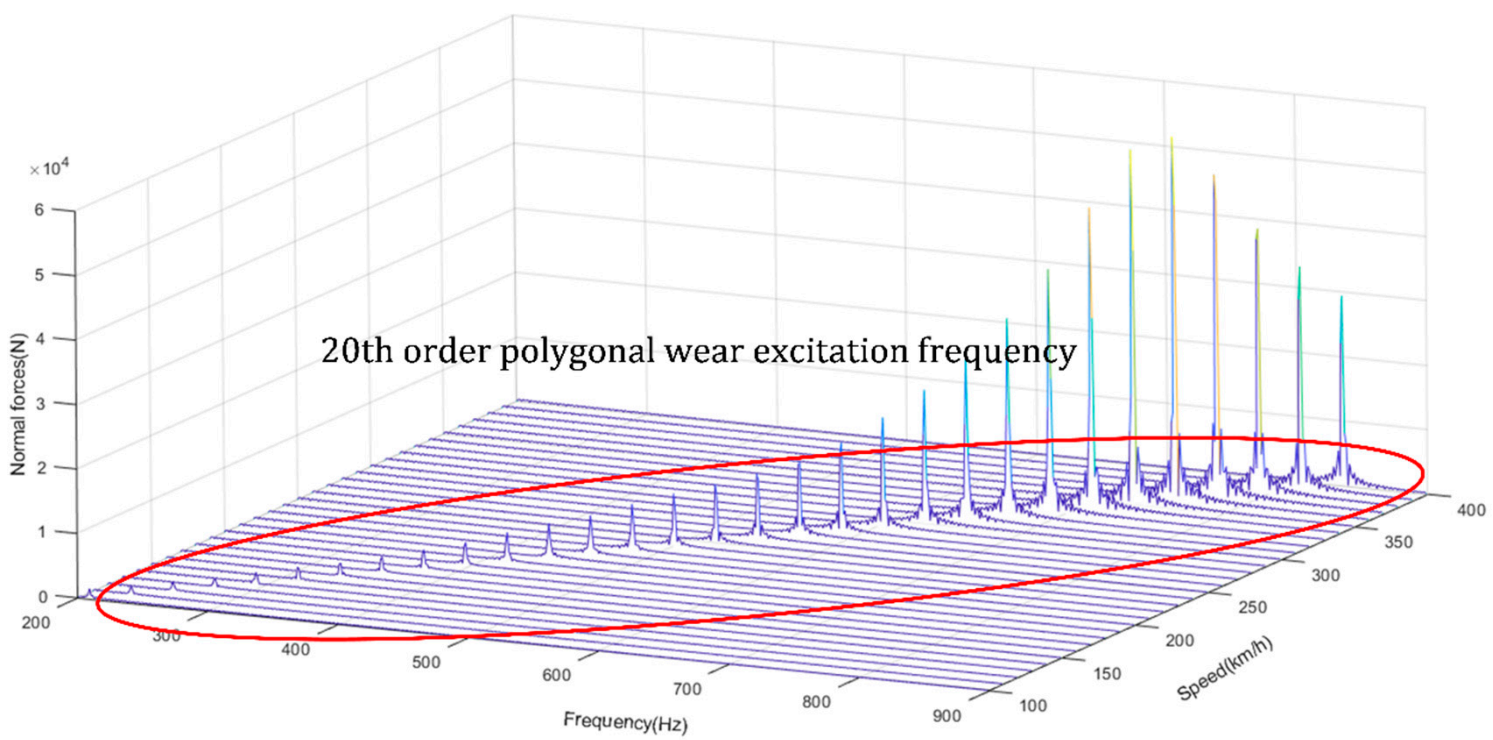

Figure 11. The relationship between the wheel-rail force and the running speed under 20th wheel wear.

The spectrum analysis of the vertical vibrate acceleration at each speed level is shown in Figure 12. With the increase in the running speed, the excitation caused by the wheel polygonization leads to an increase in the vertical vibration acceleration of the gearbox. However, unlike the wheel-rail force law, the amplitude of the gearbox vibration suddenly increases in the two speed ranges around $200 \mathrm{~km} / \mathrm{h}$ and $280 \mathrm{~km} / \mathrm{h}$. According to the running speed and wheel radius, the 20th wheel polygonal wear excitation frequency is calculated to be $411 \mathrm{~Hz}$ and $576 \mathrm{~Hz}$ at speeds of $200 \mathrm{~km} / \mathrm{h}$ and $280 \mathrm{~km} / \mathrm{h}$, respectively, which is in the resonance range of the gearbox eigenfrequencies $(405 \mathrm{~Hz}$ and $578 \mathrm{~Hz})$ in Section 2.2. It indicates that the gearbox is resonating in these speed ranges and causing abnormal vibration acceleration. When the speed exceeds $360 \mathrm{~km} / \mathrm{h}$, the wheel-rail force decreases with increasing speed in Figure 11. Nevertheless, the vibration acceleration of the gearbox increases with speed, which is also an abnormal vibration caused by the resonance of the gearbox, since the gearbox has an eigenfrequency of $927 \mathrm{~Hz}$. 


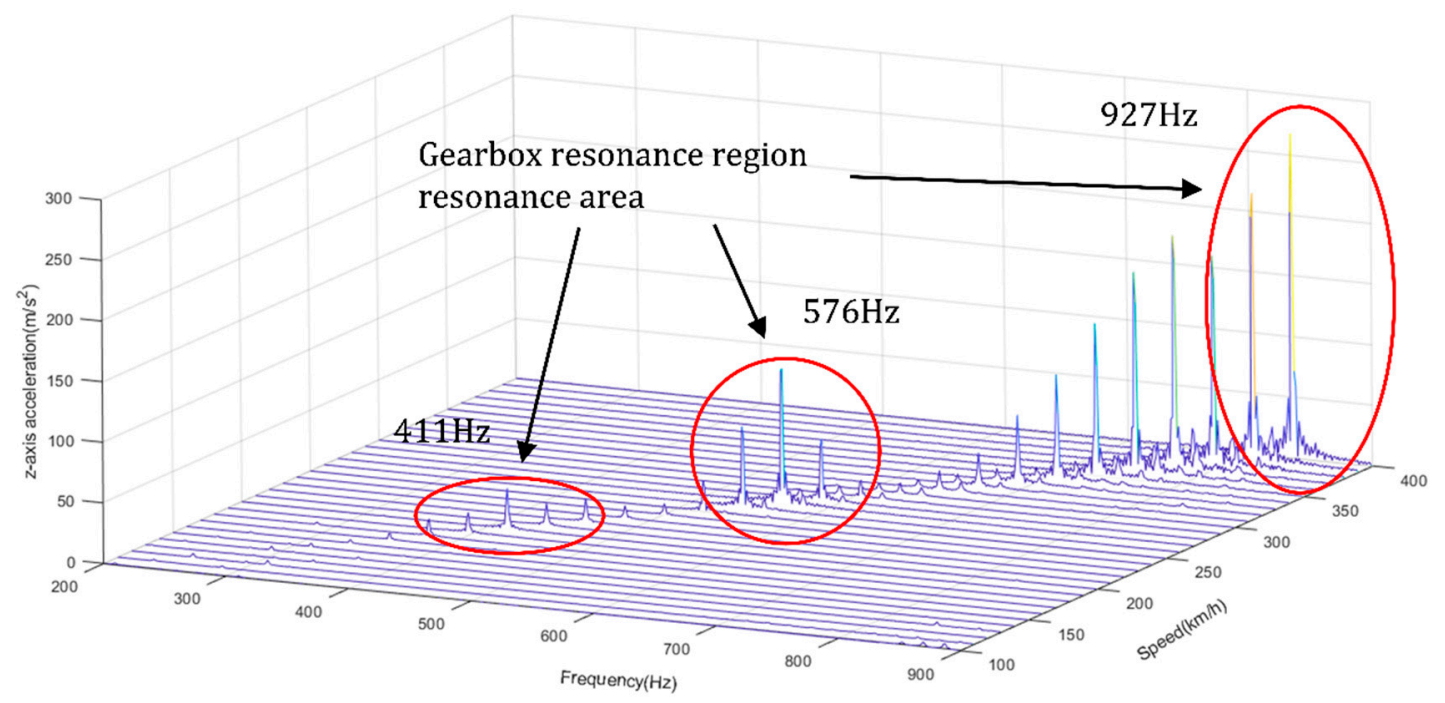

Figure 12. The vertical vibration acceleration of gearbox housing under 20th wheel wear.

As shown in Figure 13, dynamic stress and vibration acceleration have the same frequency domain characteristics and reach the peak at $411 \mathrm{~Hz}$ and $576 \mathrm{~Hz}$ due to resonance. This shows that when the high-speed train wheel polygon wear causes modal resonance of the gearbox, the dynamic stress of the gearbox will increase sharply. If it is operated under the wheel polygon wear condition for a long time, it will lead to the acceleration of fatigue damage accumulation in the gearbox.

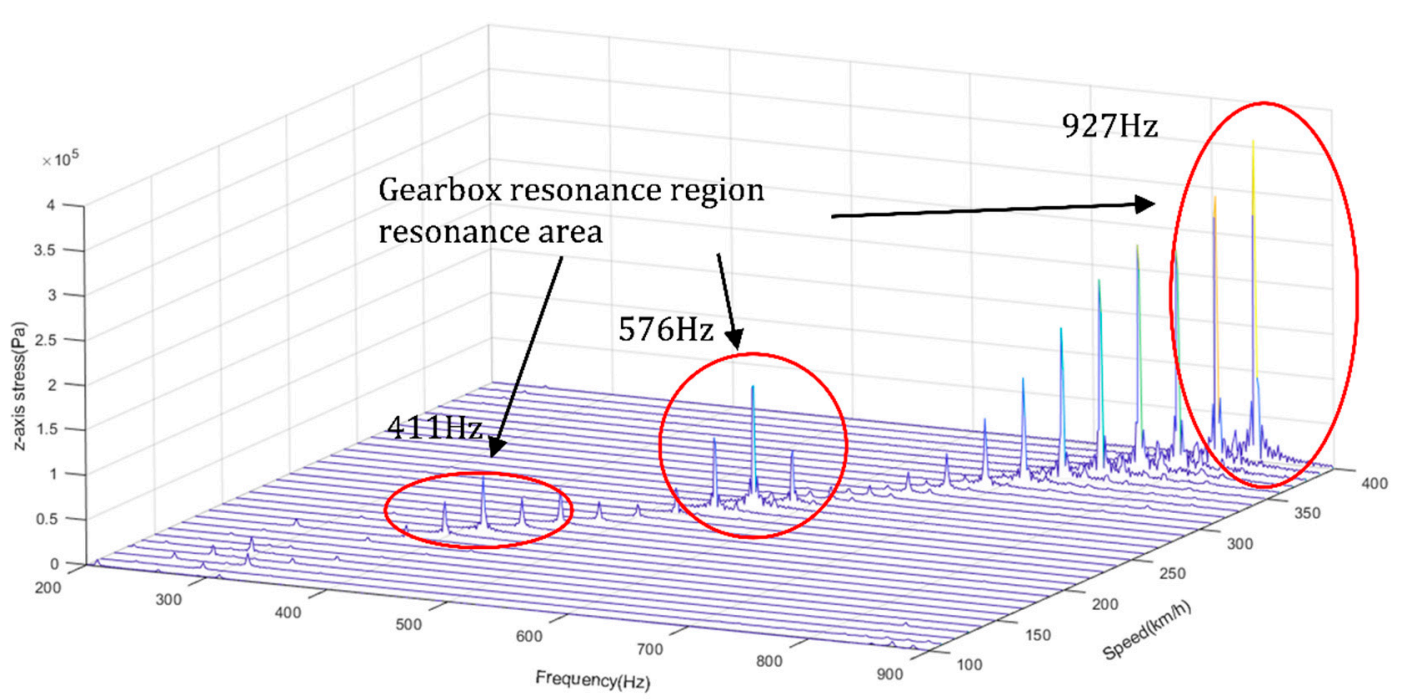

Figure 13. The dynamic stress of the gearbox housing under 20th order wheel wear.

With the continuous increase in the vehicle operating mileage, the wear on the wheel will also increase. In order to study the influence of the polygonal wear amplitude of the wheel on the dynamic stress of the gearbox, the dynamic stress of the gearbox is calculated when the vehicle runs at the speed of $280 \mathrm{~km} / \mathrm{h}$ under the condition that the amplitude of the 20th order polygonal wear amplitude range from $0.01 \mathrm{~mm}$ to $0.08 \mathrm{~mm}$. It can be seen from Figure 14 that the maximum and average values of dynamic stresses in the gearbox increase as the polygon amplitude increases. When the amplitude of wheel polygon wear increases from $0.01 \mathrm{~mm}$ to $0.08 \mathrm{~mm}$, the maximum stress amplitude increases by 50 times and the average stress increases by 2.5 times. At present, the formation mechanism of wheel polygon wear is not clear. According to the theory related to structural failure degradation, it is known that in order to slow down the process of structural fatigue 
damage accumulation, the deterioration of wheel polygon wear should be controlled by wheel turning in a timely manner [33-35].

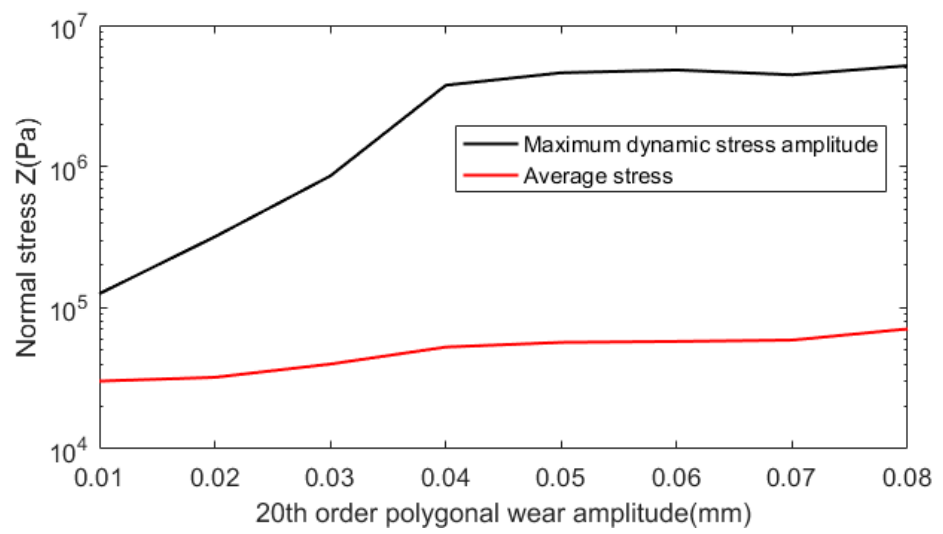

Figure 14. Dynamic stress of gearbox housing with the amplitude of 20th wheel wear.

\subsection{Effect of Traction Torque}

In order to study the effect of traction torque on the dynamic stress of the gearbox, vehicle dynamics models with and without gearing were developed separately. The simulation parameters are as follows: the 20th order polygon wear amplitude is $0.01 \mathrm{~mm}$, the vehicle speed is $280 \mathrm{~km} / \mathrm{h}$, the traction torque of the gearbox is $800 \mathrm{Nm}$, and the wheelset is considered as a rigid body. The dynamic stress of the oil surface observation hole of the gearbox is shown in Figure 15.

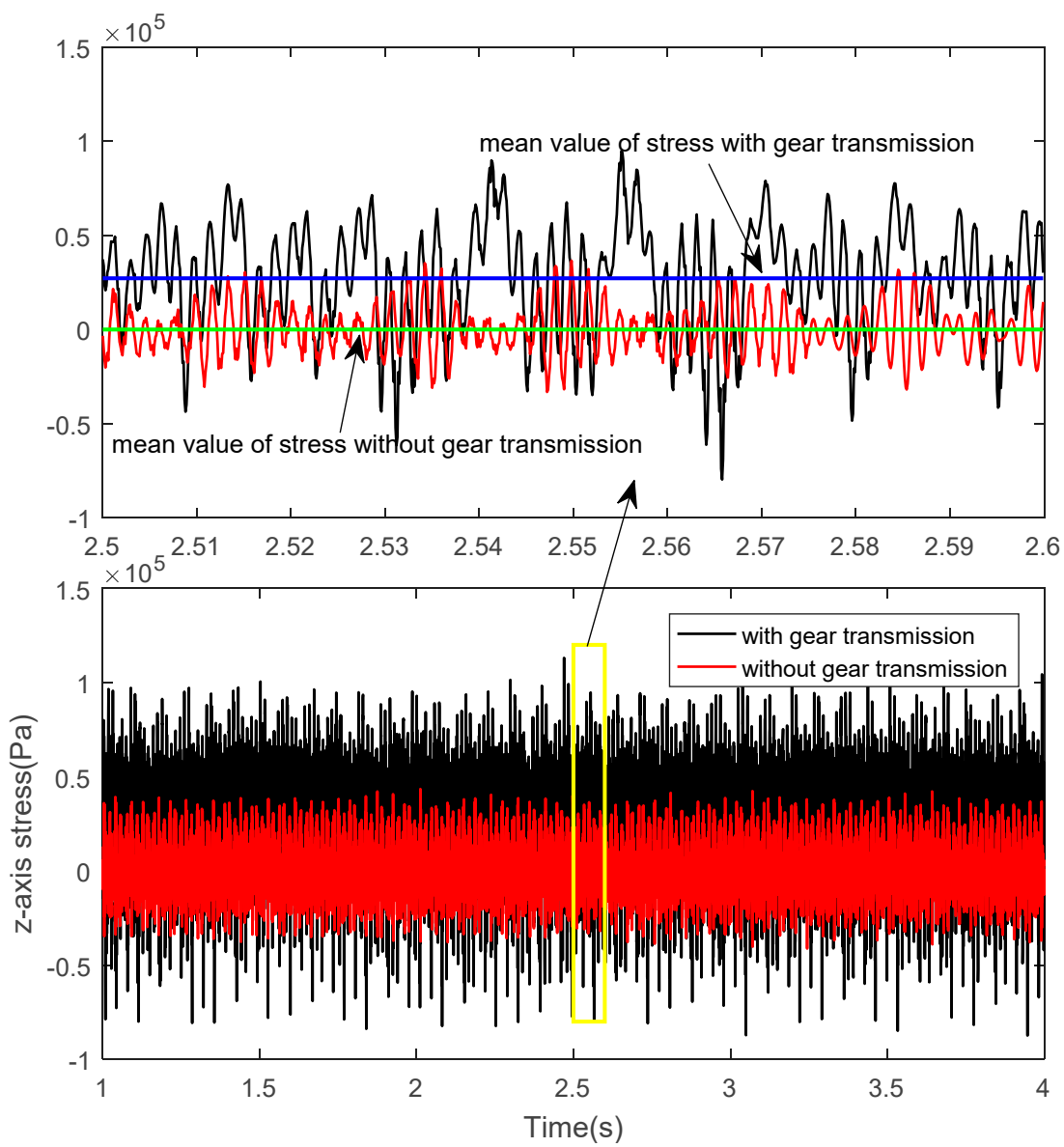

Figure 15. Effect of gear meshing on the stress of the gearbox housing. 
It can be seen that the mean value of dynamic stress of gearbox is $27,000 \mathrm{~Pa}$ considering the effect of time-varying stiffness of gear transmission, fluctuating within the range of $-80,000 \sim 100,000 \mathrm{~Pa}$. As a comparison, the average stress in the gearbox without considering the gear meshing condition is $19 \mathrm{~Pa}$, and the stress value fluctuates from $-40,000$ to 40,000 Pa.

The spectra of both situations are compared in Figure 16. From the figure, it can be seen that the gearbox stress spectrum contains more harmonic components when considering gearing conditions. In the low frequency band, $\mathrm{f}_{1}$ and $\mathrm{f}_{2}$ and their multiples appear, where $f_{1}$ and $f_{2}$ represent the active and passive wheel rotation frequencies of the gearbox, respectively, and the main frequency of gear meshing and the side frequency band appear at $2500 \mathrm{~Hz}$. In addition, the stress amplitude at $\mathrm{f}_{1}$ and the main frequency of the wheel polygon increases significantly. It follows that when the gearbox has torque input, the time-varying excitation of the gear mesh stiffness and the wheel polygon excitation of the wheel track are coupled with each other, and the effect on the gearbox stress is not just a simple superposition of the stress response under the two excitations.

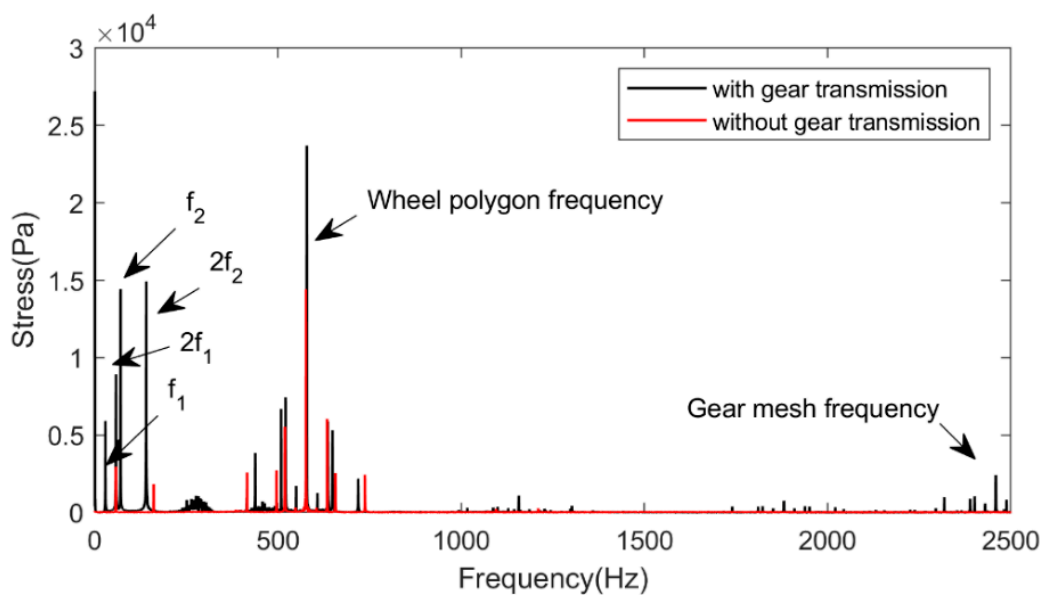

Figure 16. Spectra of the stress of the gearbox housing considering gear transmission.

\subsection{Effect of the Elastic Deformation of the Wheelset}

Based on the parameter settings in Section 3.2, the wheelset was considered as a flexible body in this section for simulation to study the influence of the elastic deformation of the wheelset on the dynamic stress of the gearbox housing. In the comparison of the dynamic stress of the gearbox housing with the elastic wheelset and that with the rigid wheelset, Figure 17 indicates that the maximum dynamic stress of the gearbox housing with the flexible wheelset reaches $367,194 \mathrm{~Pa}$, while the maximum of the dynamic stress of the gearbox housing with the rigid wheelset is $114,489 \mathrm{~Pa}$. The maximum dynamic stress of the gearbox housing with the wheelset deformation is three times larger than that without the elastic deformation of the wheelset. The dynamic stress of the gearbox housing with flexible wheelset shows the waveform with a period of $0.034 \mathrm{~s}$, which is exactly the wheelset's rotation period at $280 \mathrm{~km} / \mathrm{h}$.

The spectral analysis of the gearbox stresses under the flexible and rigid wheel pairs is shown in Figure 18. Compared with the rigid wheel pair, the gearbox stresses appear more abundant in harmonic components, such as $4 f_{1}$ and $6 f_{1}$, in the low frequency band, after considering the wheel pair flexibility. Additionally, the stress amplitude of the original harmonic components, such as $\mathrm{f}_{1}, \mathrm{f}_{2}, 2 \mathrm{f}_{1}$, and $2 \mathrm{f}_{2}$, increases significantly, and the same phenomenon also appears at the wheel polygon band and the gear mesh band. It indicates that the three factors of wheel pair elastic deformation, traction torque, and wheel polygon present a more complex coupling phenomenon in the gearbox. 


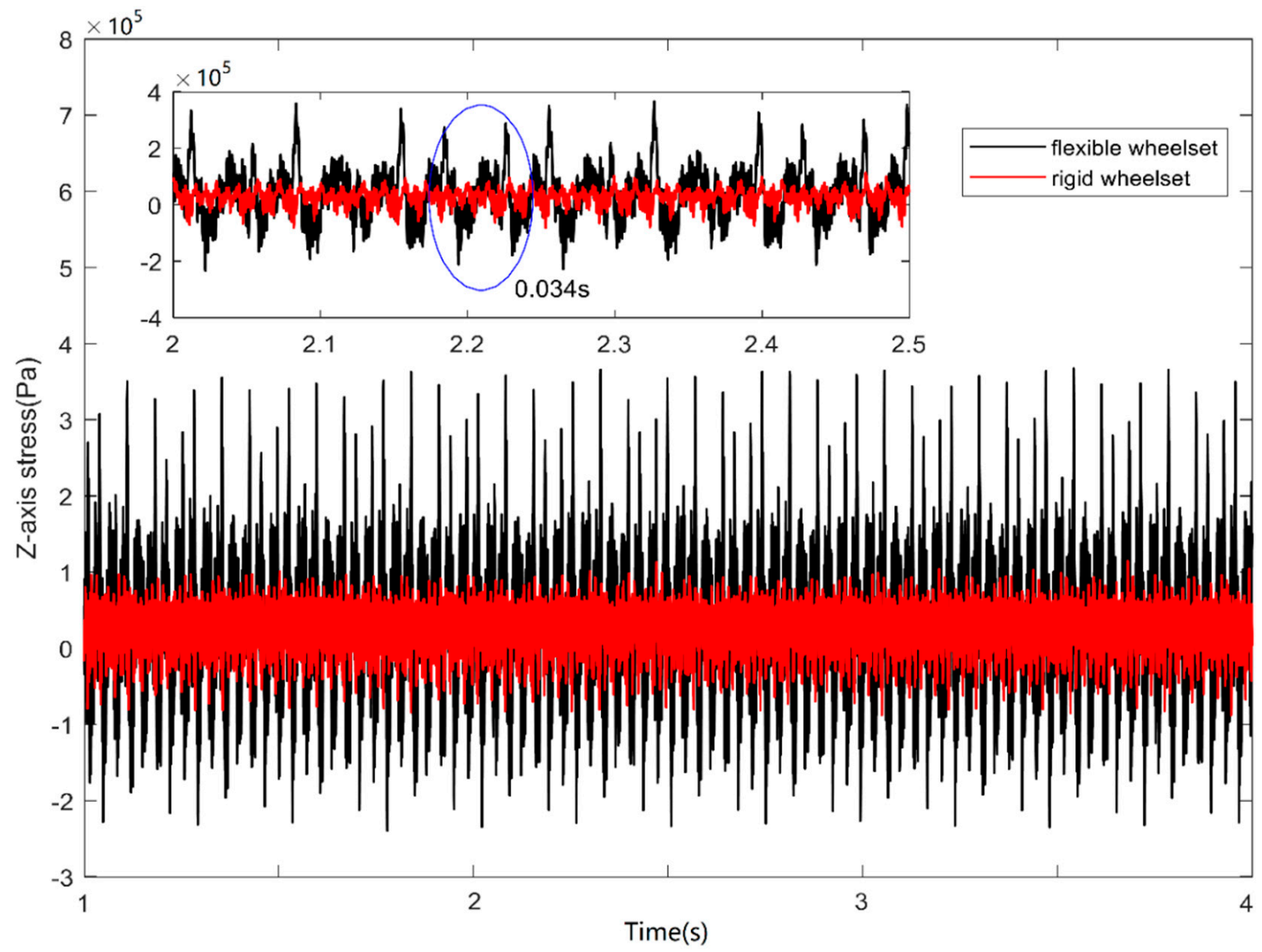

Figure 17. Effect of wheelset elastic deformation on dynamic stress of gearbox.

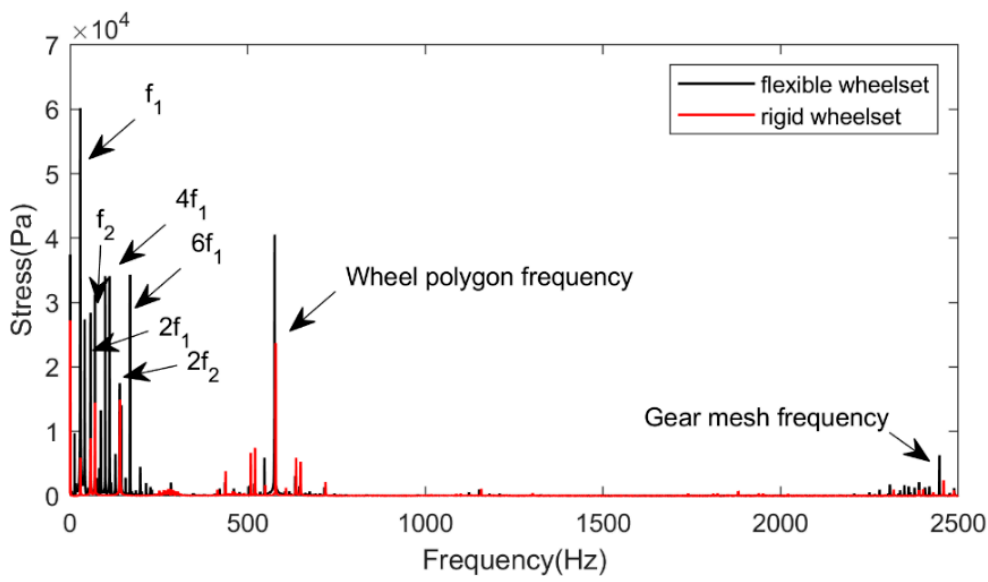

Figure 18. Spectra of the stress of the gearbox housing considering gear transmission.

\section{Actual Excitations Comprehensive Simulation}

In the actual operation of the vehicle, the wear of the left and right wheels are different, and the left and right sides of the rail have vertical irregularities. Therefore, real wheel profiles on the left and right side of a wheelset are measured by the SDS measurement instrument with the uncertainty of $0.05 \%$. The wear of the left and right wheels on the circumference is shown in Figure 19. Figure 19a,b indicate the wheel polygonization in the polar coordinate system, Figure 19c,d indicate the irregularity spectrum of polygonal wear. A real track vertical irregularity was adopted as shown in Figure 20. The traction torque and the wheelset elastic deformation are also considered when calculating the dynamic stress of gearbox housing. 

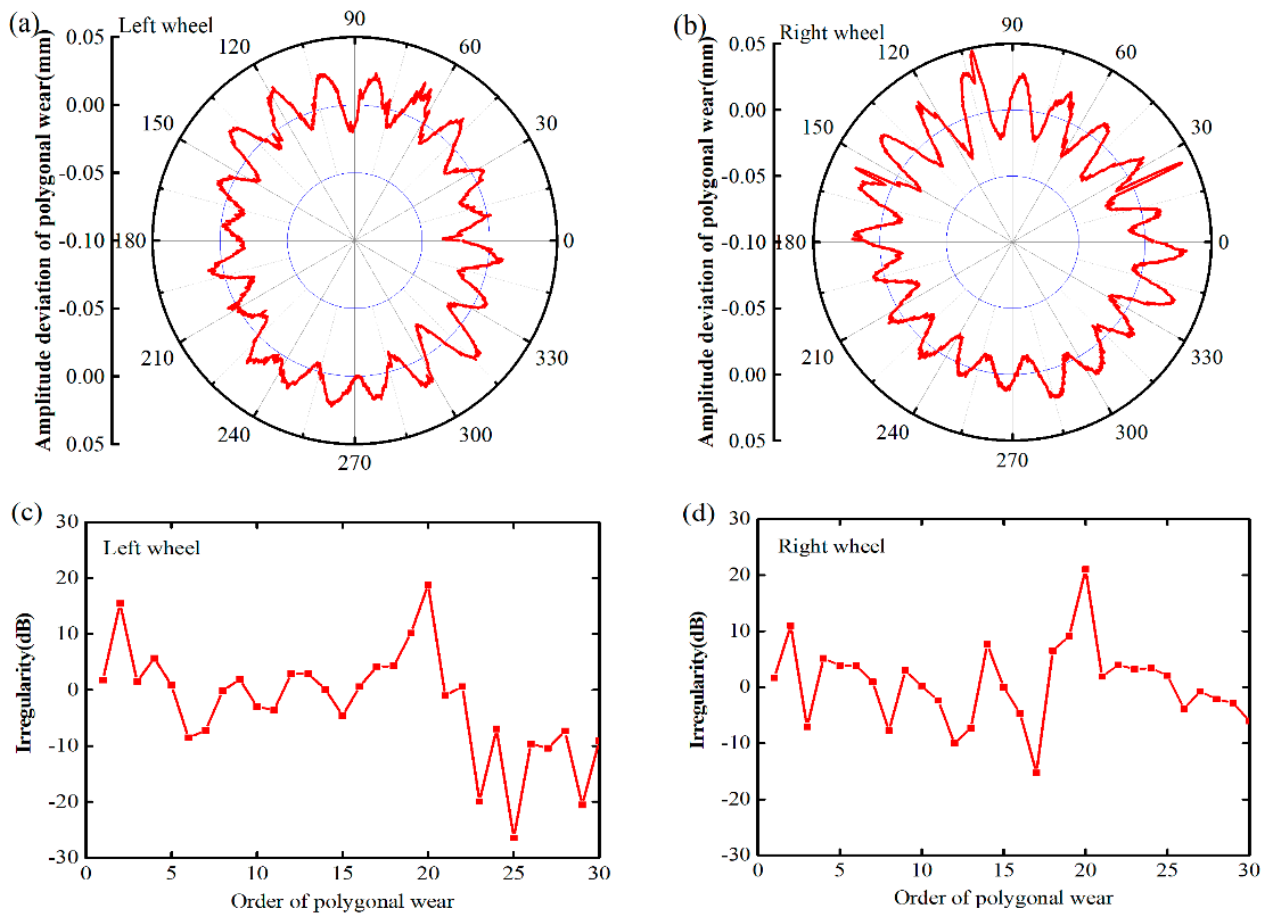

Figure 19. Measured wheel polygonal wear.(a) left wheel (b) right wheel in the polar coordinate system; the irregularity spectrum of (c) left wheel (d) right wheel.

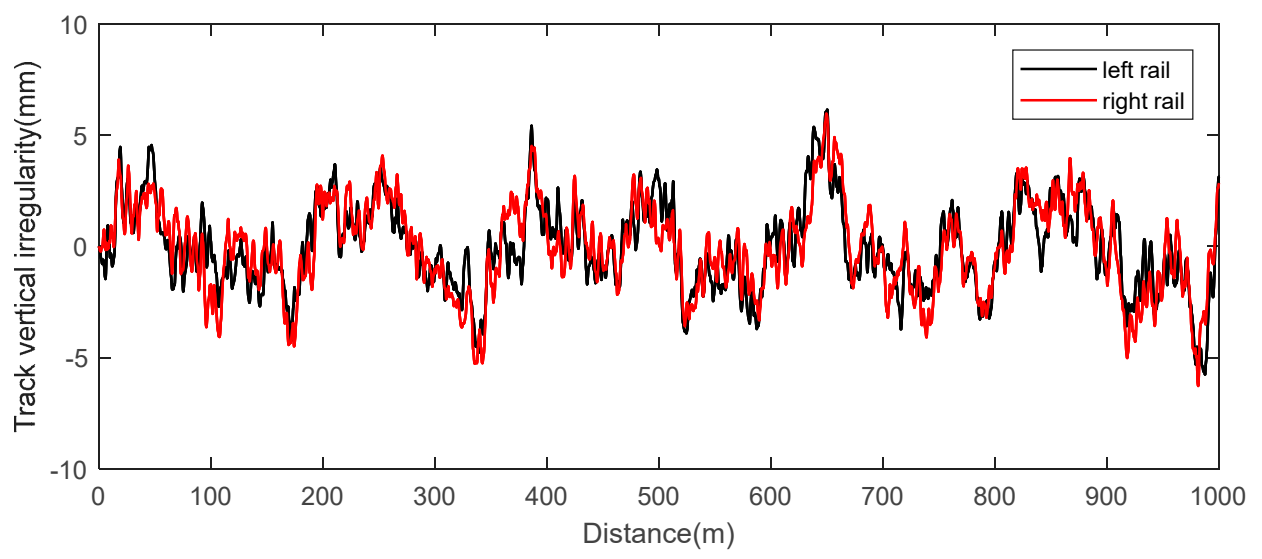

Figure 20. Track vertical irregularity.

Since the position of the gearbox is closer to the right wheel in the Y-direction, the right wheel has a greater influence on the vibration of the gearbox housing than the left wheel. Hence, the irregularity of the right wheel is used to compare with the spectrum of the vertical vibration acceleration of the gearbox. As shown in Figure 21, there are multiple dominant vibration frequencies in the vertical vibration acceleration of the gearbox that differ by $29 \mathrm{~Hz}$, which is the wheelset rotational frequency when the vehicle is running at $280 \mathrm{~km} / \mathrm{h}$. Each vibration frequency can correspond to a certain order of the wheel polygonization, and the amplitude of the main vibration frequency is consistent with the distribution of the irregularity of the wheel polygonization. The simulation results of the vibration characteristics of the transmission case agree with the experimental results in Section 2.3, indicating that the simulation of the transmission vibration characteristics, based on the vehicle dynamics model established in this paper, has sufficient accuracy. 

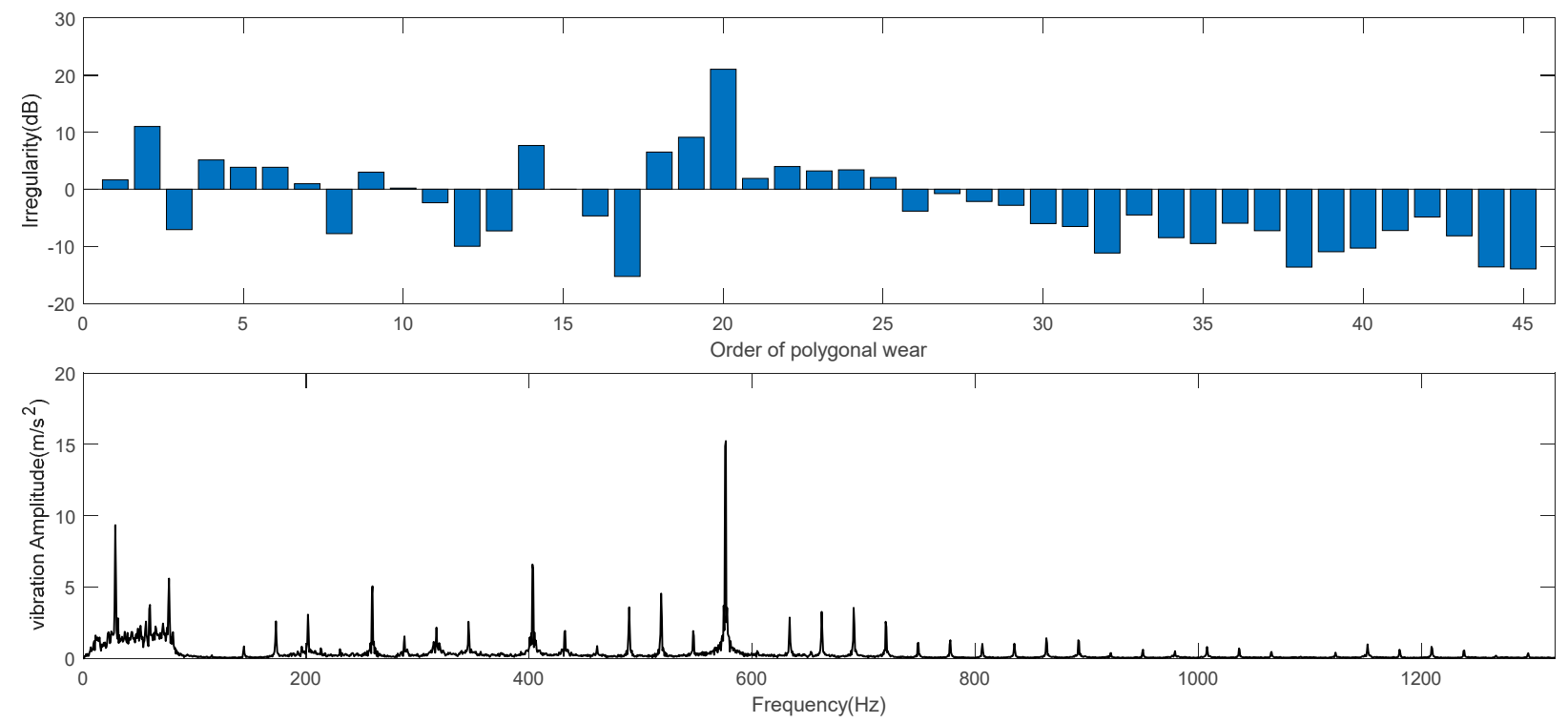

Figure 21. Gearbox vertical vibration acceleration.

Figure 22 shows the calculation results of the dynamic stress of the gearbox at $280 \mathrm{~km} / \mathrm{h}$. In the time domain diagram, the maximum stress in the Z-axis direction of the gearbox reaches 1.3 MPa. It can be seen from the frequency spectrum diagram that the primary frequency distribution of the dynamic stress and the vibration acceleration of the gearbox is basically the same, and a primary frequency occurs every $29 \mathrm{~Hz}$. In the stress spectrum, the main frequency of $144 \mathrm{~Hz}$ is obvious. After calculating the eigenvalues of the railway vehicle system, it is found that $144 \mathrm{~Hz}$ is the eigenfrequency of the wheelset roll mode, and it is also the excitation frequency of the 5th wheel polygonization at a speed of $280 \mathrm{~km} / \mathrm{h}$. As a result, the rolling motion of the wheelset was stimulated. There is only one degree of freedom of rotation about the Y-axis between the gearbox and the wheelset, so that the gearbox is torsionally deformed when the wheelset rolls around the Y-axis, which increases the local gearbox stress.
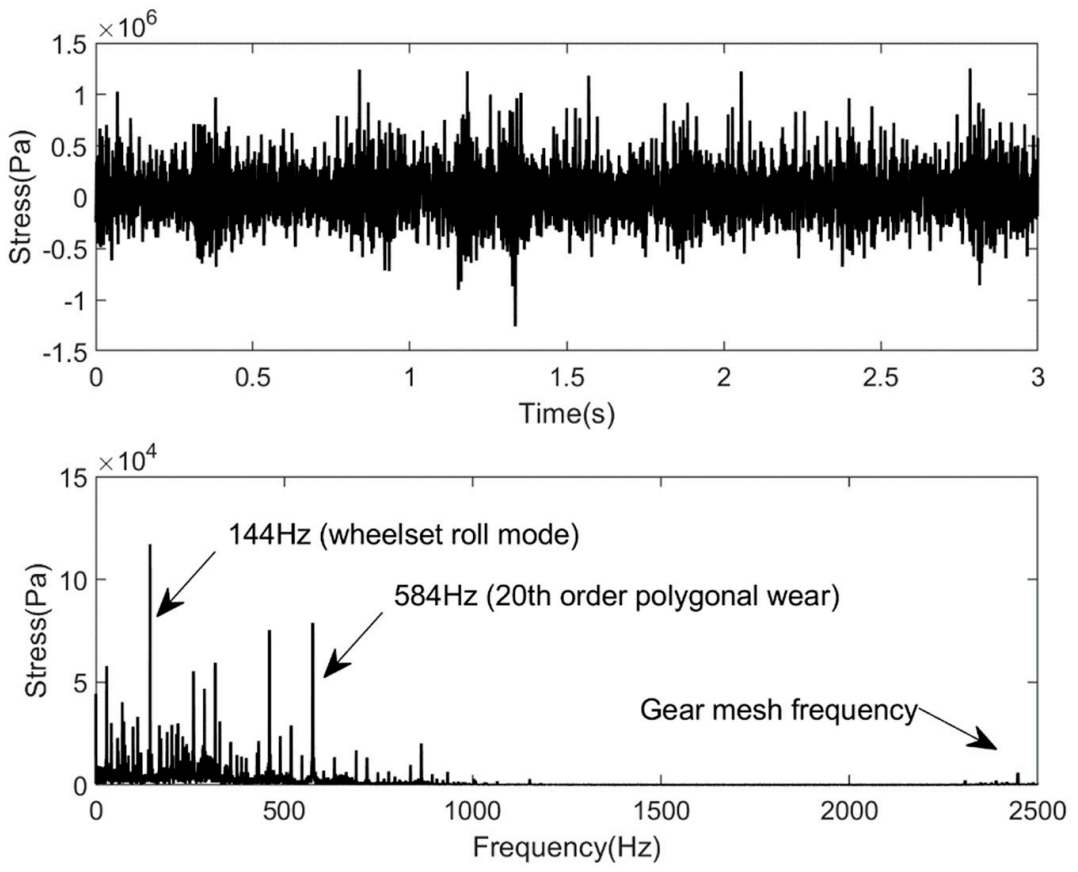

Figure 22. Gearbox dynamic stress. 


\section{Conclusions}

This paper analyzes the vibration acceleration data of the measured gearbox, divides the main frequencies of the gearbox vibration according to the forced vibration and resonance characteristics, and investigates the causes of each main frequency vibration. Considering the impact of the three excitation sources-which are the polygonal wear of wheel, the elastic deformation of the wheelset, and the time-variable meshing stiffness-on the vibration of the gearbox, the following conclusions can be drawn:

(1) The gearbox is constrained to the wheelset by a bearing. There is only a single degree of freedom about the Y-axis rotation between the two structures. Therefore, when studying the vibration of the gearbox and calculating the dynamic stress, the wheelset elastic deformation and the wheelset roll motion should be considered. Moreover, due to the traction torque, the gears of the gearbox mesh closely with each other, further strengthening the coupling relationship between the wheel pair and the gearbox.

(2) There is multi-order of the wheel polygonization, so the excitation caused by the polygonal wear of the wheel is also a wide-band excitation. Not only the 20th order wheel polygon wear excitation will increase the stress caused by the resonance of the gearbox, but also the 5th order polygonal wear of the wheel, which causes the wheelset roll motion to lead to a significant increase in the local stress of the gearbox.

Author Contributions: Conceptualization and methodology, W.Z. and H.W.; software, W.Z.; validation, W.Z. and H.W.; formal analysis, W.S.; investigation, W.Z.; resources, W.S.; data curation, H.W.; writing-original draft preparation, W.Z.; writing-review and editing, H.W.; visualization, W.S.; supervision, W.S.; project administration, H.W.; funding acquisition, H.W. All authors have read and agreed to the published version of the manuscript.

Funding: This research was funded by the National Natural Science Foundation of China, grant number U1934202.

Institutional Review Board Statement: Not applicable.

Informed Consent Statement: Not applicable.

Data Availability Statement: Data are contained within the article.

Conflicts of Interest: The authors declare no conflict of interest.

\section{References}

1. Guo, J.; Zheng, H.; Li, B.; Fu, G.-Z. A Bayesian Approach for Degradation Analysis with Individual Differences. IEEE Access 2019, 7, 175033-175040. [CrossRef]

2. Yuan, R.; Li, H.; Wang, Q. Simulation-based design and optimization and fatigue characteristics for high-speed backplane connector. Adv. Mech. Eng. 2019, 11, 1687814019856752. [CrossRef]

3. Li, H.; Guedes Soares, C.; Huang, H.Z. Reliability analysis of a floating offshore wind turbine using Bayesian networks. Ocean Eng. 2020, 217, 107827. [CrossRef]

4. Guo, J.; Zheng, H.; Li, B.; Fu, G.-Z. Bayesian Hierarchical Model-Based Information Fusion for Degradation Analysis Considering Non-Competing Relationship. IEEE Access 2019, 7, 175222-175227. [CrossRef]

5. Li, H.; Deng, Z.-M.; Golilarz, N.A.; Soares, C.G. Reliability analysis of the main drive system of a CNC machine tool including early failures. Reliab. Eng. Syst. Saf. 2021, 215, 107846. [CrossRef]

6. Xu, Z.; Wei, J.; Zhang, S.; Liu, Z.; Chen, X.; Yan, Q.; Guo, J. A state-of-the-art review of the vibration and noise of wind turbine drivetrains. Sustain. Energy Technol. Assess. 2021, 48, 101629. [CrossRef]

7. Li, H.; Yuan, R.; Fu, J. A Reliability Modeling for Multi-Component Systems Considering Random Shocks and Multi-State Degradation. IEEE Access 2019, 7, 168805-168814. [CrossRef]

8. Duan, T.; Wei, J.; Zhang, A.; Xu, Z.; Lim, T.C. Transmission error investigation of gearbox using rigid-flexible coupling dynamic model: Theoretical analysis and experiments. Mech. Mach. Theory 2021, 157, 104213. [CrossRef]

9. Li, H.; Diaz, H.; Soares, C.G. A developed failure mode and effect analysis for floating offshore wind turbine support structures. Renew. Energy 2021, 164, 133-145. [CrossRef]

10. Yuan, R.; Tang, M.; Wang, H.; Li, H. A Reliability Analysis Method of Accelerated Performance Degradation Based on Bayesian Strategy. IEEE Access 2019, 7, 169047-169054. [CrossRef]

11. Yuan, R.; Li, H.; Gong, Z.; Tang, M.; Li, W. An enhanced Monte Carlo simulation-based design and optimization method and its application in the speed reducer design. Adv. Mech. Eng. 2017, 9, 1687814017728648. [CrossRef] 
12. Li, H.; Teixeira, A.P.; Soares, C.G. A two-stage Failure Mode and Effect Analysis of offshore wind turbines. Renew. Energy 2020, 162, 1438-1461. [CrossRef]

13. Abbes, M.S.; Fakhfakh, T.; Haddar, M.; Maalej, A. Effect of transmission error on the dynamic behavior of gearbox housing. J. Adv. Manuf. Technol. 2007, 34, 211-218. [CrossRef]

14. Chaari, F.; Fakhfakh, T.; Haddar, M. Dynamic analysis of a planetary gear failure caused by tooth pitting and cracking. J. Fail. Anal. Prev. 2006, 6, 73-78. [CrossRef]

15. Litak, G.; Friswell, M.I. Dynamics of a gear system with faults in meshing stiffness. Nonlinear Dyn. 2005, 41, 415-421. [CrossRef]

16. Ding, H.; Kahraman, A. Interactions between nonlinear spur gear dynamics and surface wear. J. Sound Vib. 2007, 307, 662-679. [CrossRef]

17. $\mathrm{Wu}, \mathrm{X} . ; \mathrm{Chi}, \mathrm{M} . ; \mathrm{Wu}, \mathrm{P}$. Influence of polygonal wear of railway wheels on the wheel set axle stress. Veh. Syst. Dyn. 2015, 53, 1535-1554. [CrossRef]

18. Yuan, R.; Li, H.; Wang, Q. An enhanced genetic algorithm-based multi-objective design optimization strategy. Adv. Mech. Eng. 2018, 10, 1687814018784836. [CrossRef]

19. Wang, Z.; Allen, P.; Mei, G.; Wang, R.; Yin, Z.; Zhang, W. Influence of wheel-polygonal wear on the dynamic forces within the axle-box bearing of a high-speed train. Veh. Syst. Dyn. 2019, 58, 1385-1406. [CrossRef]

20. $\mathrm{Wu}, \mathrm{H} . ; \mathrm{Wu}, \mathrm{P} . ; \mathrm{Xu}, \mathrm{K} . ; \mathrm{Li}, \mathrm{F}$. Finite element model updating using crow search algorithm with Levy flight. Int. J. Numer. Methods Eng. 2020, 121, 2916-2928. [CrossRef]

21. Li, H.; Díaz, H.; Soares, C.G. A failure analysis of floating offshore wind turbines using AHP-FMEA methodology. Ocean Eng. 2021, 234, 109261. [CrossRef]

22. Huang, G.H.; Wang, X.Y.; Mei, G.M.; Zhang, W.; Liang, S. Dynamic response analysis of gearbox housing system subjected to internal and external excitation in high-speed Train. J. Mech. Eng. 2015, 51, 95-100. [CrossRef]

23. Wang, Z.; Mei, G.; Zhang, W.; Cheng, Y.; Zou, H.; Huang, G.; Li, F. Effects of polygonal wear of wheels on the dynamic performance of the gearbox housing of a high-speed train. Proc. Inst. Mech. Eng. Part F J. Rail Rapid Transit 2018, 232, 1852-1863. [CrossRef]

24. Hu, W.; Liu, Z.; Liu, D.; Hai, X. Fatigue failure analysis of high speed train gearbox housings. Eng. Fail. Anal. 2017, 73, 57-71. [CrossRef]

25. Liu, Y.; Qiao, N.; Zhao, C.; Zhuang, J. Vibration Signal Prediction of Gearbox in High-Speed Train Based on Monitoring Data. IEEE Access 2018, 6, 50709-50719. [CrossRef]

26. Fakhfakh, T.; Chaari, F.; Haddar, M. Numerical and experimental analysis of a gear system with teeth defects. Int. J. Adv. Manuf. Technol. 2005, 25, 542-550. [CrossRef]

27. Shi, H.; Wang, J.; Wu, P.; Song, C.; Teng, W. Field measurements of the evolution of wheel wear and vehicle dynamics for high-speed trains. Veh. Syst. Dyn. 2018, 56, 1187-1206. [CrossRef]

28. Yuan, R.; Li, H. A multidisciplinary coupling relationship coordination algorithm using the hierarchical control methods of complex systems and its application in multidisciplinary design optimization. Adv. Mech. Eng. 2017, 9, 1687814016685222 [CrossRef]

29. Wu, X.; Rakheja, S.; Qu, S.; Wu, P.; Zeng, J.; Ahmed, A. Dynamic responses of a high-speed railway car due to wheel polygonalisation. Veh. Syst. Dyn. 2018, 56, 1817-1837. [CrossRef]

30. Wu, H.; Wu, P.; Li, F.; Shi, H.; Xu, K. Fatigue analysis of the gearbox housing in high-speed trains under wheel polygonization using a multibody dynamics algorithm. Eng. Fail. Anal. 2019, 100, 351-364. [CrossRef]

31. Sun, Y.; Guo, Y.; Chen, Z.; Zhai, W. Effect of Differential Ballast Settlement on Dynamic Response of Vehicle-Track Coupled Systems. Int. J. Struct. Stab. Dyn. 2018, 18, 1850091. [CrossRef]

32. Li, H.; Guo, J.-Y.; Yazdi, M.; Nedjati, A.; Adesina, K.A. Supportive emergency decision-making model towards sustainable development with fuzzy expert system. Neural Comput. Appl. 2021, 33, 15619-15637. [CrossRef]

33. Yuan, R.; Meng, D.; Li, H. Multidisciplinary reliability design optimization using an enhanced saddlepoint approximation in the framework of sequential optimization and reliability analysis. Proc. Inst. Mech. Eng. Part O J. Risk Reliab. 2016, 230, 570-578. [CrossRef]

34. Li, F.; Wu, H.; Wu, P. Vibration fatigue dynamic stress simulation under non-stationary state. Mech. Syst. Signal Process. 2021, 146, 107006. [CrossRef]

35. Li, H.; Huang, H.-Z.; Li, Y.-F.; Zhou, J.; Mi, J. Physics of failure-based reliability prediction of turbine blades using multi-source information fusion. Appl. Soft Comput. 2018, 72, 624-635. [CrossRef] 